\title{
Climate Change Is Unavoidable
}

\author{
Jan-Erik Lane \\ University of Freiburg, Germany \\ E-mail: janeklane@googlemail.com
}

Received: April 4, 2012

Accepted: May 16, 2012

Online Published: August 16, 2012

doi:10.5430/rwe.v3n2p1

URL: http://dx.doi.org/10.5430/rwe.v3n2p1

\begin{abstract}
One may show that $\mathrm{CO} 2$ emissions per GDP unit of economic output have fallen over time as well as that this ratio is smaller in rich than in poor countries. However, one cannot conclude that a halt to the growth in total emissions is likely in the future. Similarly, one may show that the $\mathrm{CO} 2$ emissions per capita are much larger in rich and emerging economies than in poor countries. But one cannot conclude that total emissions can be reduced only by sharp reductions in rich countries. $\mathrm{CO} 2$ emissions are driven by economic production, using massive amounts of energy, and emerging economies with high rates of economic and huge populations pollute as much as rich countries, if not more like China.
\end{abstract}

Keywords: CO2 equivalent emissions, GDP, Global warming, Climate change, Jevon's paradox, Emissions per capita and per GDP unit, Environmental Kuznets curve, Kiribati and ecocide, Resiilience

\section{Introduction}

There are three components in the global warming phenomenon: temperature rise, the emission of $\mathrm{CO} 2$ equivalent pollution and economic activity. The exact relationship between the first two components is not known, as how much the $\mathrm{CO} 2$ emissions raise the global temperature is not known exactly. But the second relationship - between economic production or output and $\mathrm{CO} 2$ emissions - can be pinned down in a rather precise manner. Since economic output leads to more $\mathrm{CO} 2$ emissions, and more of $\mathrm{CO} 2$ emissions must somehow result in higher global temperatures, one may conclude that global warming is unstoppable. This is the message of the argument presented here, where we analyse the connection between economic production and $\mathrm{CO} 2$ equivalent emissions.

We look at different aspects of the relationship between $\mathrm{CO} 2$ equivalent emissions and the standard measure of economic activity, country GDP. One may examine a variety of aspects like $\mathrm{CO} 2$ per GDP unit, $\mathrm{CO} 2$ per capita and $\mathrm{CO} 2 / \mathrm{GDP}$ per capita. What is decisive for the prediction of future $\mathrm{CO} 2$ emissions is total GDP. As total $\mathrm{CO} 2$ emissions are a positive function of total GDP, one cannot expect emissions to stop increasing, unless economic growth would become negative globally.

\section{Plans to Reduce $\mathrm{CO} 2$}

A number of plans have been proposed in order to halt the sharp increase in CO2 equivalent emissions since the 1970s, with the hope that this form of pollution could be stabilised at some level in the future. Besides the international agreement at Kyoto, various country governments have launched different reduction schemes. But to no avail, one must admit, because the $\mathrm{Co} 2$ emissions just keep going up.

The recently available 2011 emission figures confirm the impression that the $\mathrm{CO} 2$ problematic constitutes a Juggernaut type phenomenon. The unstoppable push towards increase in $\mathrm{CO} 2$ equivalent emissions stems from the close association between $\mathrm{CO} 2$ emissions and economic activity. To explain why these plans - international and national ones - have failed to halt the growth in $\mathrm{CO} 2$ emissions, one need not resort to game theory and the PD game, depicting how rational players fail to coordinate due to myopia and opportunism. It is enough to analyse the close connection between $\mathrm{CO} 2$ type emissions and economic production or output.

Earlier studies have researched a so-called environmental Kuznets Curve $(E K C)$, which hypothesizes that the relationship between per capita income and the use of natural resources and/or the emission of wastes has an inverted U-shape. At low levels of income, the emission of wastes increases with income. Beyond some turning point, the emission of wastes declines with income. Now, one has to be clear about the variables specified in this equation: Is it 
the emissions per GDP unit or emissions per capita, because higher income (GDP) always means more of emissions? When calculating the entire effect upon total emissions, one must keep in mind that more of income or GDP implies more of emissions as well as that population size matters crucially for total emissions (Stern, 2004).

\section{Economic Output, or GDP}

Recently, there has been a debate on the pros and cons of the standard GDP measure, some scholars arguing that it is not comprehensive enough, and in need of being enlarged to include other aspects of well-being than income (Stiglitz et al, 2010). Although it sounds appealing to take into account other aspects than production like income distribution or the experience of happiness, one must recognize that the GDP indicator is highly informative about basics in economic activity, focusing upon the refined measurement of economic output. If we follow classical economist Say in underlining the huge role of supply in economic life, then we would wish to analyse the connection between economic production and pollution.

The standard GDP indicator remains a superior tool for tapping the economic activity in a country, although it does not include the informal sector of the economy. Economic life is dominated by production, which leaves an immense impression upon the country, including pollution. And human beings need economic output to stay alive and also prosper. All forms of economic activity have repercussions for the production of $\mathrm{CO} 2$ equivalent emissions. One may measure these emissions sector by sector in the economy.

\section{The Basic Connection between Economy and Emissions}

Economic output has a clear and determinate impact upon this type of pollution, i.e. the $\mathrm{CO} 2$ equivalent emissions. Every dollar of increased economic activity leaves an imprint in the form of some kilo of $\mathrm{CO} 2$ equivalent emission. This is hardly surprising, given that economic production employs energy and energy consumption results in pollution. However, this basic connection has not been employed when suggesting sharp reductions in emissions. To make all talk about halting $\mathrm{CO} 2$ emissions realistic, one needs a baseline onto which such reductions may be related. We suggest that this baseline is the GDP of a country.

Figure 1 shows the general relationship between global economic output and $\mathrm{CO} 2$ equivalent emissions. It is crystal clear that the connection is very tight, with $\mathrm{c}=0.615 \mathrm{~kg} / \mathrm{USD}$ and $\mathrm{R} 2=0.969$ in a simple regression.

$<$ Insert Figure 1 Here $>$

As economic growth powers ahead in the global market economy, $\mathrm{CO} 2$ emissions cannot be halted. Economic activity requires huge amounts of energy, which in turn leads to massive emissions. Global demand for energy is predicted to growth sharply over the next two decades, according to the scenario of Energy Information Administration. Even if several countries would move to use less polluting energy production mechanisms, the trend would still be upwards, as global economic activity powers ahead.

It is true that economic development promotes more of efficiency with regard to $\mathrm{CO} 2$ emissions - see Figure 2.

$<$ Insert Figure 2 Here $>$

Even if this ratio declines, the basic connection between GDP and $\mathrm{CO} 2$ emissions remains positive, meaning that huge increases in economic activity entails increases in total $\mathrm{CO} 2$ equivalent emissions. This amounts to the well-known Jevon's paradox: "It is wholly a confusion of ideas to suppose that the economical use of fuel is equivalent to a diminished consumption. The very contrary is the truth." (http://www.newyorker.com/reporting/2010/12/20/101220fa_fact_owen).

The connection between GDP and $\mathrm{CO} 2$ equivalent emissions may be analysed in more detail, which reveals some interesting findings about emissions per capita as well as emissions per GDP unit.

\section{Emissions per Capita}

The $\mathrm{CO} 2$ equivalent emissions constitute a form of pollution that is forthcoming especially in rich countries and rapidly developing ones, i.e. where economic activity is high or expanding quickly. Figure 3 displays the substantial difference between the $\mathrm{CO} 2$ emissions per capita in rich and poor countries over time.

$<$ Insert Figure 3 Here $>$

However, it is not only rich countries that have large per capita emissions. As Figure 4 shows, also countries with high levels of economic growth like e.g. China are characterized by high levels of per capita emissions.

$<$ Insert Figure 4 Here $>$ 
Yet, the paradox of the global emissions situation is that it is not always the countries with high per capita emissions that display the largest total emissions. It all depends upon the size of the population.

\section{Emissions per GDP Unit}

An entirely different perspective upon the $\mathrm{CO} 2$ equivalent emissions in the countries of the world is attained when one examines the ratio of emissions per GDP unit to the GDP. Figure 5 shows that this ratio is much higher in low income countries than in rich countries - i.e. only here are there signs of an EKC.

$<$ Insert Figure 5 Here $>$

The same relationship - the more affluent, the less the ratio between emissions and GDP - holds not only over time but also cross-sectionally.

Looking at Figure 6, one may be tempted to conclude that the increase in the $\mathrm{CO} 2$ emissions will soon come to a halt, as emerging economies reach higher levels of affluence, characterized by a low ratio emission/GDP. Yet, the growth in economic output is so large that $\mathrm{CO} 2$ emissions will continue to increase massively.

$<$ Insert Figure 6 Here $>$

\section{Conclusion}

Much of the $\mathrm{CO} 2$ equivalent emissions are produced by the so-called G 20 countries. It includes not only the mature economies of the world but also the so-called emerging economies. Figure 7 shows the largest polluters.

$<$ Insert Figure 7 Here $>$

No agreement about halting this form of pollution of the global atmosphere is likely, because it would hurt global economic activity. As global output is predicted to rise over the next decades, so energy consumption and emissions will increase. The conclusion is merely a question of logic: Global warming is set to occur during the 21 rst century. But no one knows with how much, meaning that it is impossible to predict the consequences.

Yet, the only realistic strategy is resilience. It is reported that some of the states in the Pacific have started to plan for the future, which could involve the drowning of their entire set of islands. Thus, Kiribati and Tuvalu is looking for new ground where to locate their populations entirely. Kiribati hopes for a place on one of the Fiji Islands. Other countries may decide similarly to start planning for a future where climate change is inevitable the Maldives. The 21 rst century will no doubt be the century of climate change with all its attending consequences for mankind and the states of the world.

\section{References}

Cornillie, J., \& Fankhauser, S. (2004). The Energy Intensity of Transition Countries. Energy Economics, 26, 283-295.

Egli, H. (2002). Are Cross-Country Studies of the Environmental Kuznets Curve Misleading? New Evidence from Time Series Data for Germany. FEEM Working Paper 25.

Friedl, B., \& Getzner, M. (2003). Determinants of CO2 emissions in a small open economy. Ecological Economics, 45(1), 133-148.

Grossman, G. M., \& Krueger, A.B. (1995). Economic Growth and the Environment. Quarterly Journal of Economics, 110(2), 353-77.

Hamilton, C., \& Turton, H. (2002). Determinants of emissions growth in OECD countries. Energy Policy, 30, 63-71.

Heil, M.T., \& Selden, T.M. (2001). Carbon Emissions and Economic Development: Future Trajectories Based on Historical Experience. Environment and Development Economics, 6, 63-83.

Moomaw, W. R., \& Unruh, G. C. (1997). Are Environmental Kuznets Curves Misleading Us? The Case of CO2 Emissions. Environment and Development Economics, 2(4), 451-463.

Olivier, J.G.O., G. Janssens-Maenhout, J. A.H.W. Peters, \& J. Wilson. (2011). Long Term Trends in Global CO2 Emissions. 2011 Report - Background Studies. PBL Netherlands, Environmental Assessment Agency, the Hague.

Shafik, N. (1994). Economic Development and Environmental Quality: An Econometric Analysis. Oxford Economic Papers 46, 757-773.

Shafik, N., \& Bandyopadhyay, S. (1992). Economic Growth and Environmental Quality: Time Series and Gross Country Evidence. Washington, DC: The World Bank. 
Stern, D.I. (1998). Progress on the Environmental Kuznets Curve? Environment and Development, 3,175-198.

Stern, D.I. (2004). Environmental Kuznets Curve. Encyclopaedia of Energy, 3, Elsevier.

Stiglitz, J.E., A. Sen, \& J-P. Fitoussi. (2010). Mismeasuring Our Lives: Why GDP Doesn't Add Up. New York: The New Press.

World Bank Databank. (2012). [Online] Available: http://databank.worldbank.org/data/home.aspx

World Bank indicators - GDP constant 2000 US\$. [Online] Available: http://data.worldbank.org/indicator/NY.GDP.MKTP.KD

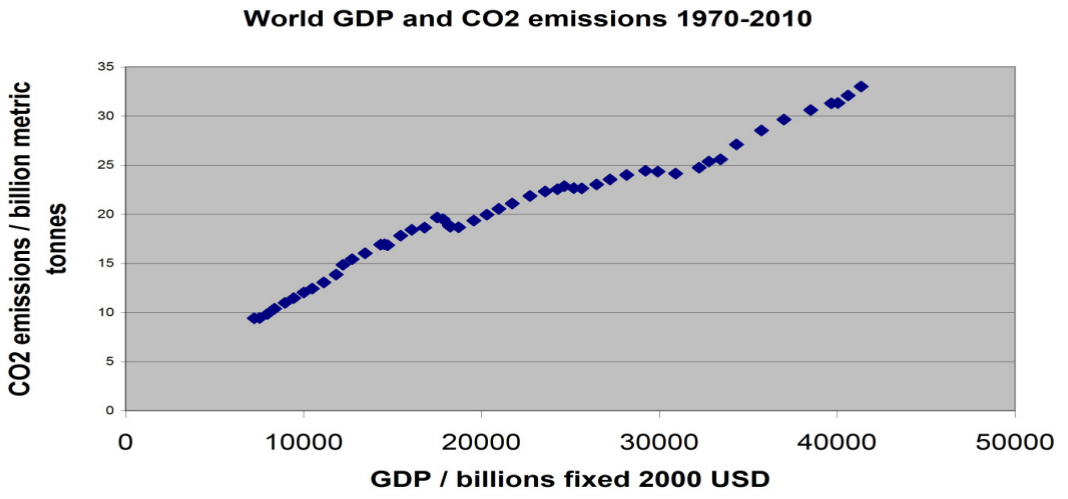

Figure 1. GDP and $\mathrm{CO} 2$ equivalent emissions over time

Sources: GDP from World Bank indicators - GDP constant 2000 US\$; http://data.worldbank.org/indicator/NY.GDP.MKTP.KD; CO2 from. Olivier et al (2011): Long Term Trends in Global CO2 Emissions. 2011 Report-Background Studies. PBL Netherlands, Environmental Assessment Agency, the Hague.

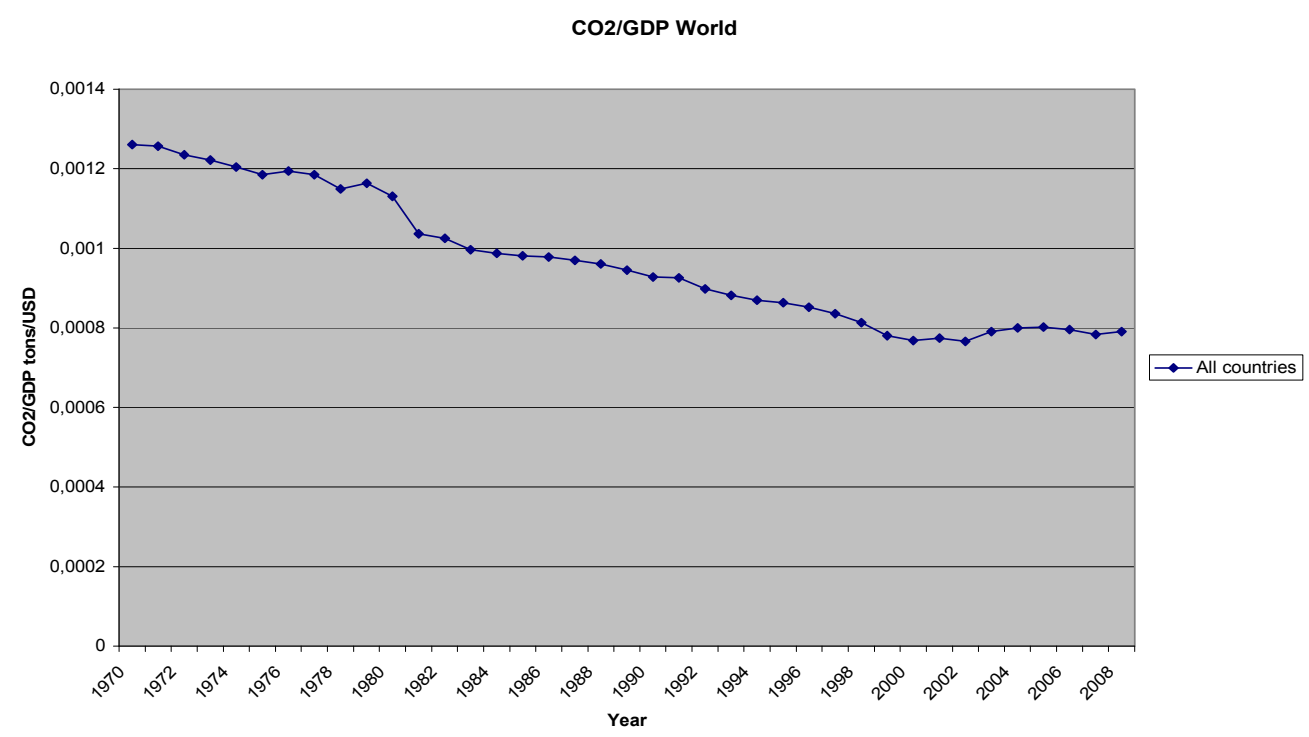

Figure 2. The ratio of $\mathrm{CO} 2$ emissions to GDP over time 


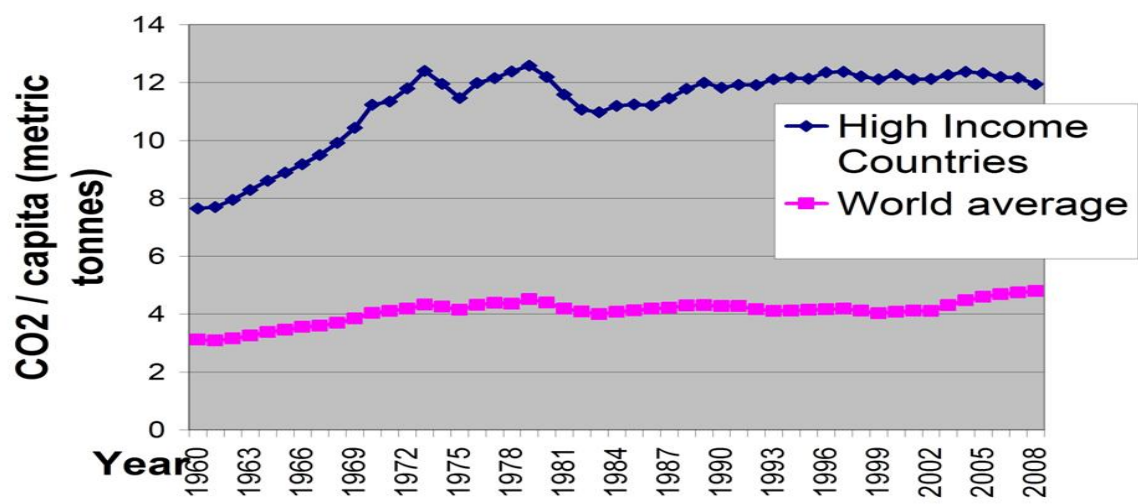

Figure 3. CO2 emissions per capita 1960-2008

Note: A high-income economy is defined by the World Bank as a country with a gross national income per capita of $\$ 12,276$ USD or more in 2010. Low income country $=\$ 1,005$ or less. World Bank, Country Classification.

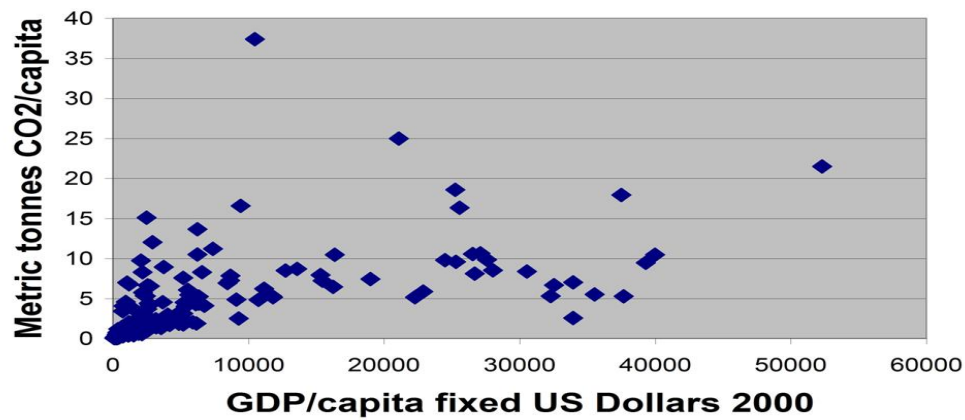

Figure 4. Per capita emissions and GDP per capita 2008

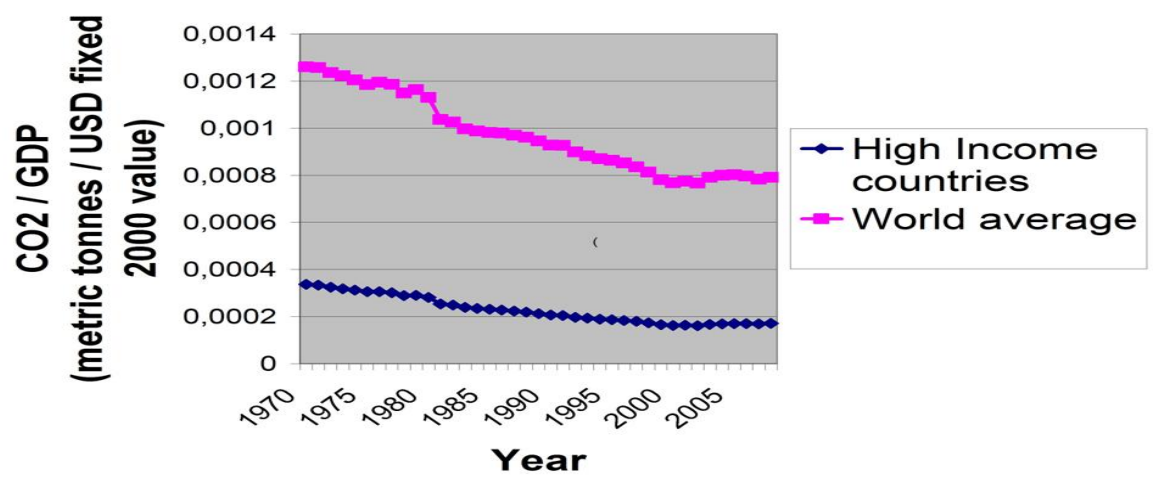

Figure 5. Ratio of $\mathrm{CO} 2$ emissions per GDP unit to country GDP over time

Note: A high-income economy is defined by the World Bank as a country with a gross national income per capita of $\$ 12,276$ USD or more in 2010. World Bank, Country Classification. 


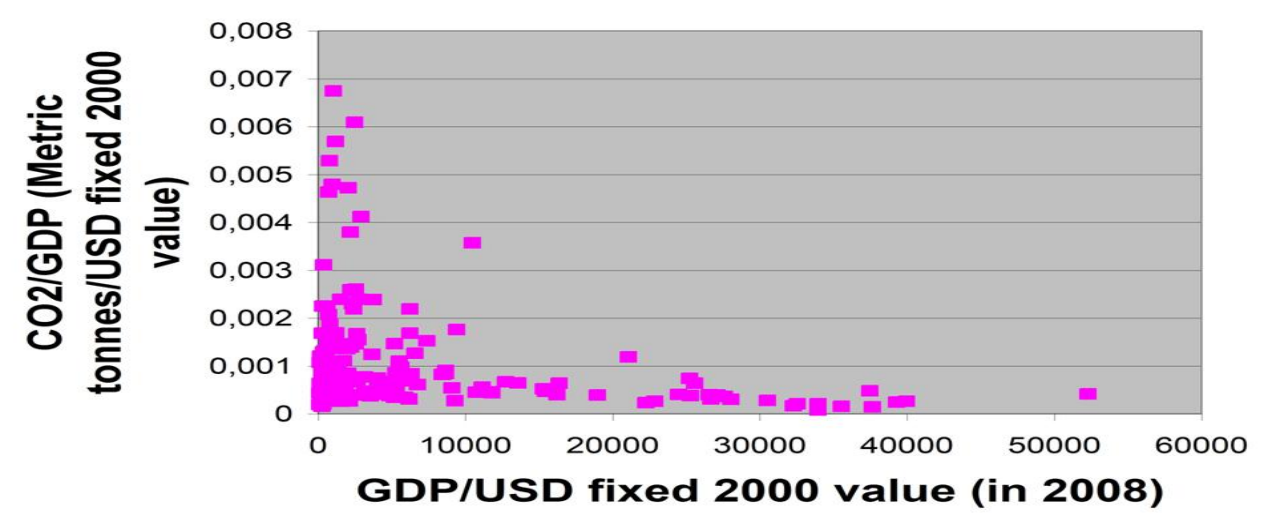

Figure 6. Ratio of emissions to GDP 2008

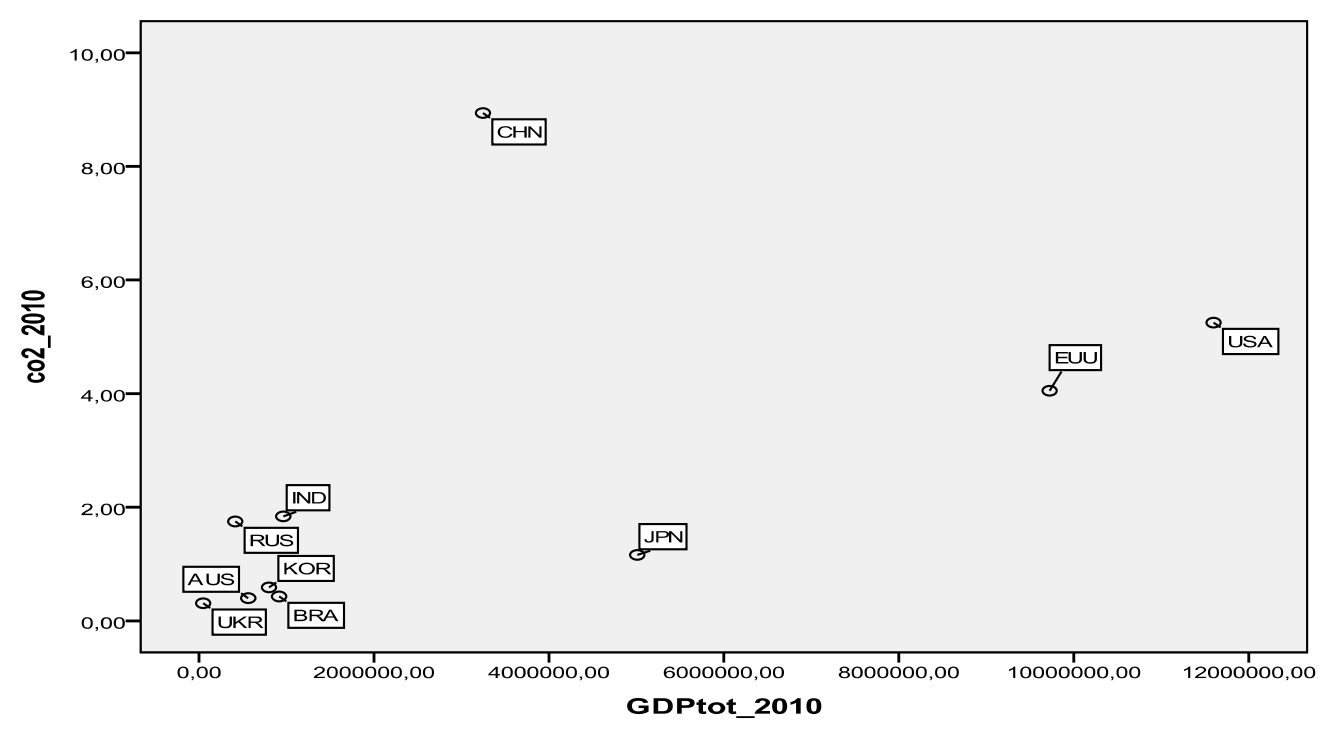

Figure 7. Total emissions and GDP per country 2010

Note: Emissions in billion mega tons; GDP is trillions US dollars. Sources: Emissions: Olivier et al (2011); GDP World Bank Databank (2012; http://databank.worldbank.org/data/home.aspx) 